\title{
PENINGKATAN KEMAMPUAN GURU DALAM MENYUSUN SOAL COMPUTER BASED TESTMELALUI IN-HOUSE TRAINING
}

\section{INCREASING TEACHERS' ABILITY IN CREATING COMPUTER BASED TEST QUESTIONS THROUGH IN-HOUSE TRAINING}

\author{
SLAMET UTOMO \\ SMA Islam Cikal Harapan 2
}

\begin{abstract}
Received: March 09, 2021 Computer Based Test (CBT) plays an important role to support efficient and faster formative Revised: September 30, 2021 and summative evaluations conducted by teachers in schools. The purpose of this research is to Accepted: November 26, 2021 improve the teacher's ability in preparing CBT questions. The research was conducted at SMA Islam Cikal Harapan 2 for the 2019/2020 academic year involving 10 teachers. The type of this research is a school action research (PTS), two cycles, with stages of planning, implementation, observation, and reflection. Collecting data using the technique of questionnaires, documentation and tests. The results of the study revealed that the percentage of teachers' ability to create CBT questions increased from $60 \%$ in the first cycle to $87 \%$ in the second cycle. These abilities include preparing questions, creating supporting files, and uploading questions on a computer. In addition, teacher activity in IHT increased from $73 \%$ in cycle I to $87 \%$ in cycle II. The conclusion of this research is that the ability to create CBT questions and teacher activities can be improved through in-house training.
\end{abstract}

\begin{abstract}
Abstrak.
Computer Based Test (CBT) memegang peranan penting untuk mendukung secara efisien dan lebih cepat evaluasi formatif dan sumatif yang dilakukan guru di sekolah. Peningkatan kemampuan guru dalam penyusunan soal CBT merupakan tujuan dari penelitian yang dilakukan di SMA Islam Cikal Harapan 2 Tahun Pelajaran 2019/2020 dengan melibatkan 10 guru. Penelitian ini merupakan penelitian tindakan sekolah (PTS), dua siklus, dengan tahapan perencanaan, pelaksanaan, pengamatan, dan refleksi. Pengumpulan data menggunakan teknik quesioner, dokumentasi dan tes. Hasil penelitian mengungkapkan bahwa prosentasi kemampuan guru menyusun soal CBT meningkat pada siklus I yaitu $60 \%$ menjadi $87 \%$ pada siklus II. Kemampuan menyusun CBT meliputi perancangan soal, pembuatan file pendukung, dan pengaktifan soal di komputer. Selain itu terjadi peningkatan aktivitas guru di dalam IHT dari 73\% pada siklus I menjadi $87 \%$ pada siklus II. Simpulan penelitian ini adalah IHT dapat meningkatkan aktifitas dan kemampuan guru dalam menyusun soal CBT.
\end{abstract}

Keywords: $\quad$ Computer Based Test (CBT), In-House Training, Teacher's ability, teacher's activity Kata kunci: $\quad$ computer based test (CBT), in-house training, kemampuan guru, aktivitas guru

$\left(^{\star}\right)$ Corresponding Author: utomo_cikal@yahoo.co.id

How to Cite: Utomo, S., (2021). Peningkatan Kemampuan Guru Dalam Menyusun Soal Computer Based Test Melalui In-House Training. Jurnal Lingkar Mutu Pendidikan, 18 (2), 204-209. https://doi.org/10.54124/jlmp.v18i1.33

\section{PENDAHULUAN}

Peningkatan kemampuan guru dalam menyusun soal CBT, memegang peranan penting dalam pendidikan era digital abad 21, yang menekankan peranan intervensi teknologi pembelajaran. Penggunaan teknologi di bidang pendidikan, membuat penguasaan ICT menjadi suatu kebutuhan. Evaluasi pembelajaran telah beralih dari berbasis kertas (paper) menjadi tanpa kertas (paperless), sehingga dapat dikatakan evaluasi pembelajaran yang manual beralih menjadi evaluasi pembelajaran digital.

Kondisi kemampuan guru yang tergolong rendah terkait CBT pada era digital, menuntut penyesuaian guru dalam pengetahuan, keterampilan serta ketelitian yang cukup tinggi dalam 
penguasaan komputer. Seorang tenaga pendidik selayaknya mampu menyiapkan instrumen evaluasi pembelajaran yang efektif dan menarik sehingga siswa memiliki ketertarikan untuk terus belajar dan latihan. Instrumen evaluasi belajar mengajar di kelas atau di luar kelas untuk semua tingkatan di setiap jenjang pendidikan perlu dipersiapkan. Instrumen evaluasi tersebut dapat berupa visual, audio, audio visual, multimedia dan lain-lain. Penggunaan instrumen evaluasi pembelajaran yang berbasis multimedia sudah banyak dilakukan, salah satunya adalah Computer Based Test (CBT).

Sistem evaluasi berbantuan atau Computer Based Test (CBT) adalah sistem baik penskoran, pelaksanaan tes, yang pelaksanaannya dibantu dengan komputer. CBT bertujuan membantu guru dalam melakukan evaluasi dan juga untuk mempercepat umpan balik.

Sistem CBT merupakan turunan atau pengembangan sistem pembelajaran berbantuan komputer atau Computer Assisted Instructional (CAI) yang dikhususkan untuk penilaian meliputi kumpulankumpulan soal dan proses penskoran otomatis, media audio, video dan interaktif.

Menurut (Arsyad 2014) penggunaan komputer sebagai media pembelajaran telah melalui langkah-langkah instruksional mulai dari merencanakan, mengatur, mengorganisasikan, menjadwal pengajaran, melakukan tes, mengumpulkan data mengenai peserta didik lalu melakukan analisis statistik mengenai data pembelajaran dan membuat catatan perkembangan pembelajaran.

Keuntungan Computer Based Test (CBT), diantaranya: sebagai tes yang tepat bagi siswa, dapat menghemat waktu dan memudahkan pekerjaan penilaian tes dan laporan tertuli dan peserta langsung mengetahui hasil tes. Sedangkan keurangan CBT antara lain adanya perlu mempersiapkan peralatan seperti komputer atau laboratorium komputer baik hardware, software dan jumlah. Dibutuhkan juga pengetahuan dan ketrampilan komputer tertentu ketika CBT bermasalah dalam pelaksanaan, tes berbasis komputer.

Menurut (Saad 2007) sistem Computer Based Test (CBT) memiliki beberapa keuntungan yaitu soal lebih menarik secara penampilan karena disampaikan secara multimedia, paperless sehingga mengurangi biaya kertas, penghitungan skor lebih valid dan menghemat waktu sehingga hasil dari pelaksanaan tes lebih cepat didapat untuk pengambilan keputusan.

Menurut (Dahlan, 2000) in-service training adalah upaya untuk meningkatkan pengetahuan dan keterampilan pendidik dalam bidang tertentu sesuai dengan tugasnya, kegiatan ini sangat dibutuhkan oleh para pendidik muda yang kurang berpengalaman sehingga bisa menjadi bekal dalam melaksankan tugas-tugasnya sebagai pendidik.

Secara umum, In House Training bertujuan untuk meningkatkan kualitas sumberdaya manusia pada instansi terkait, sehingga diharapkan upaya pencapaian sasaran lebih mudah dilakukan. Selain itu dapat, upaya dapat menciptakan hubungan baik antar peserta dan lebih mempererat rasa kebersamaan. Sehingga motivasi peserta maupun narasumber dalam pembiasaan budaya pembelajaran, untuk mengeksplorasi penyelesaian masalahya ng dihadapi di sekolah dan mencari solusi pemecahannya secara bersama-sama dapat meningkat.

Merujuk beberapa pendapat tersebut, maka In-House Training adalah program pelatihan yang dilaksanakan di lokasi peserta, menggunakan sumber daya dan materi yang relevan dengan permasalahan yang sedang dihadapi oleh peserta pelatihan. Diharapkan dengan program ini peserta akan lebih mudah menerima dan mempraktekkan langsung materi pelatihan untuk menjawab permasahan kerja yang sering dialami dan dapat meningkatkan kualitas dan kinerja para pendidik.

Penelitian (Murniati 2016) menemukan bahwa dengan menggunakan CBT untuk instrumen evaluasi pembelajaran dapat meningkatkan hasil belajar peserta didik. Namun demikian penelitian tersebut hampir belum ada yang menggunakan IHT sebagai alternatif pelatihan untuk meningkatkan kemampuan menyusun soal CBT. Oleh karena itu penelitian mengajukan hipotesi bahwa jika guru diberi pelatihan IHT maka kemampuan menyusun soal CBT meningkat mencapai $>75 \%$. Manfaat yang diperoleh dari Penelitian Tindakan Sekolah (PTS) adalah dapat memberikan manfaat bagi sekolah dalam memecahkan masalah guru melalui peningkatkan kemampuan guru dalam menyusun soal tes CBT melalui in house training pada SMA Islam Cikal Harapan 2 dan diharapkan dapat meningkatkan mutu pembelajaran dan peningkatan mutu sekolah. 


\section{METODE PENELITIAN}

Penelitian ini dilakukan di SMA Islam Cikal Harapan 2 yang beralamatkan di Perumahan Citra Indah City, Jonggol km 23,2 Kabupaten Bogor pada bulan Maret sampai dengan April 2019. Metode penelitian ini adalah metode Penelitian Tindakan Sekolah (Kemdiknas 2010). Subjek PTS ini adalah guru SMA Islam Cikal Harapan 2.

Penelitian Tindakan Sekolah dilakukan dengan 2 siklus. Setiap siklus terdiri atas tahap perencanaan, pelaksanaan, pengamatan dan refleksi. Tehnik pengumpulan data dalam PTS ini menggunakan : 1) angket, untuk mengetahui kemampuan guru terhadap menyusun soal CBT melalui In House Training; 2) observasi, untuk mengetahui manfaat In House Training dalam peningkatan kemampuan guru dalam menyusun soal CBT; 3) dokumentasi dari hasil penyusunan soal-soal CBT.

Data dikumpulkan pada setiap kegiatan observasi dari pelaksanaan siklus PTS kemudian dianalisis dengan tehnik deskriptif menggunakan presentase untuk melihat kecenderungan guru dalam meningkatkan kemampuannya dalam menyusun soal CBT.

\section{HASIL DAN PEMBAHASAN}

Hasil yang diperoleh pada Penelitian Tindakan Sekolah disajikan sebagai berikut.

Kemampuan guru dalam Menyusun soal CBT setelah diberi intervensi tindakan In house training pada Siklus I, disajikan pada Gambar 1.

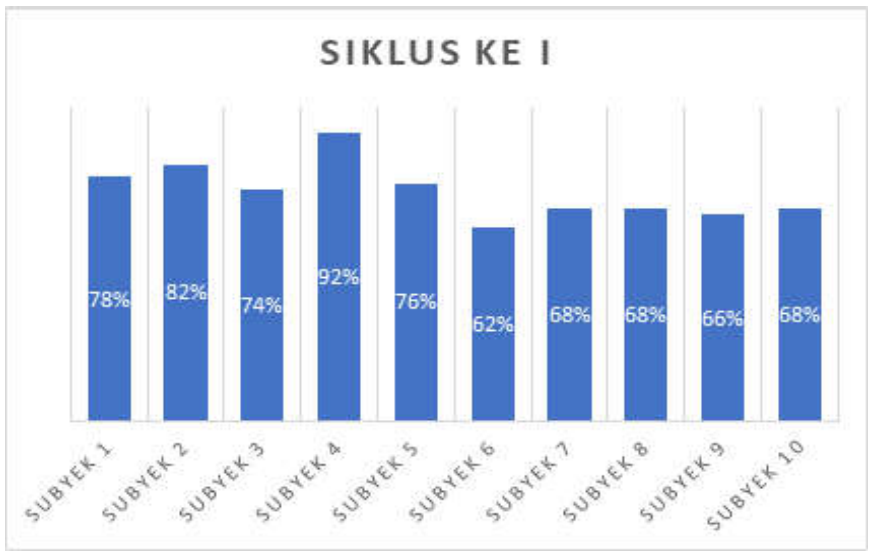

Gambar 1: Kemampuan guru menyusun soal CBT Siklus I

Berdasarkan temuan pada Gambar 1, dapat dijelaskan bahwa setelah diberi intervensi In House Training, guru sudah mulai memahami bagaimana cara membuat soal-soal CBT dan mengimplementasikan ke dalam komputer, walaupun belum semua guru berhasil dengan sempurna dalam menyelesaikan target dari pemateri, namun demikian sudah ada satu orang guru yang dapat menyusun soal-soal CBT dengan sangat baik dengan persentase $92 \%$, sedangkan guru dalam katagori baik (75\% - 85\%) sebanyak 3 guru, dan sebanyak 5 guru belum menyelsaikan penyusunan soal CBT dengan baik.

Temuan penelitian pada pelaksanaan mengungkapkan bahwa dengan tingkat ketercapaian minimal $75 \%$, ternyata terdapat 4 guru yang dapat menyelesaikan penyusunan soal CBT dan sebanyak 6 guru yang belum mampu menyesaikan penyusunan soal CBT. Capaian kemampuan menyusun soal CBT tersebut, mayoritas guru belum mampu pada tahap pengolahan data dan pengaktifan soal, tetapi sebagain besar guru sudah mampu menyelesaikan pembuatan soal CBT pada tahap pembuatan soal CBT.

Menurut peneliti bahwa dalam melakukan pembinaan dan bimbingan kepada guru-guru membutuhkan proses dan kesabaran agar tujuan dari kemampuan guru dapat dicapai dengan baik dan merata.

Secara umum, pada Siklus I seluruh Guru sudah menyusun soal-soal CBT, tetapi jika dilihat dari kriteria yang telah di tentukan tergambar bahwa belum $50 \%$ guru yang mampu menyelesaikan dengan baik pada penyusunan soal CBT. Dengan demikian, masih perlu dilakukan tindak lanjut terhadap 
kegiatan In House Training ke siklus 2, karena indikator keberhasilan In-House Training ini adalah 85\% guru mampu menyusun soal CBT dengan kriteria yang telah di tentukan. Setelah dilakukan refleksi terhadap Siklus I, ada dua hal yang perlu mendapat perhatian sebagai tindak lanjut yaitu: (1) Guru yang mampu menyelesaikan penyusunan soal CBT berdasarkan kriteria telah mencapai 73\%; (2) Tingkat ketercapaian indikator pada In house training pada penyusunan soal CBT yang masih 50\% dari kriteria 75\%, sehingga kegiatan In house training perlu dilanjutkan pada Siklus II.

Kemampuan guru dalam Menyusun soal CBT setelah diberi intervensi tindakan In house training pada Siklus II, disajikan pada Gambar 2.

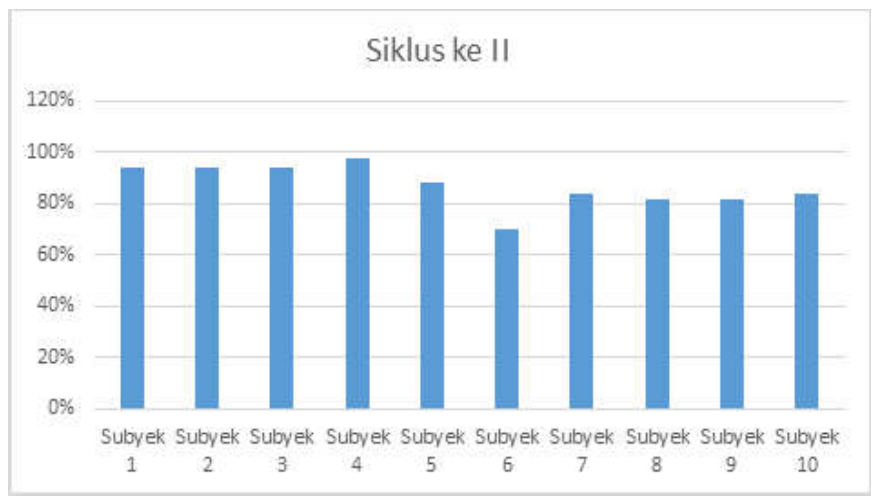

Gambar 2: Kemampuan guru menyusun soal CBT Siklus II

Berdasarkan temuan pada Gambar 2 pada Siklus II dilakukan untuk menyempurnakan hasil yang diperoleh pada Siklus I yang masih memiliki beberapa kekurangan dari kriteria yang telah ditentukan, maka adanya jeda pada pelaksanaan In House Training antara Siklus I dan Siklus II, telah memberikan kesempatan bagi guru-guru untuk meningkatkan kemampuannya dengan cara berdiskusi dan belajar sesama guru.

Kegiatan In House Training pada Siklus II dilakukan dengan pemateri yang sama dan fokus pada pengolahan data penyusunan soal-soal CBT, yang diharapkan dapat meningkatkan kemampuan guru-guru seperti kriteria yang ditetapkan sekolah.

Dari data tabel di atas terlihat, terjadi peningkatan persentase kualitas guru-guru dari rata-rata $73 \%$ menjadi $87 \%$, dan seluruh guru telah meningkat kemampuannya dalam menyusun soal CBT, dari 10 guru yang menjadi sasaran penelitian, 9 guru mencapai persentase di atas $75 \%$ dan hanya 1 guru yang masih dibawah 75\%. Artinya, pada kegiatan In house training pada Siklus II telah terjadi peningkatan kemampuan penyusunan soal CBT.

Peningkatan kemampuan guru dalam Menyusun soal CBT setelah diberi intervensi tindakan melalui In house training dari Siklus I ke Siklus II dapat di lihat seperti pada Gambar 3.

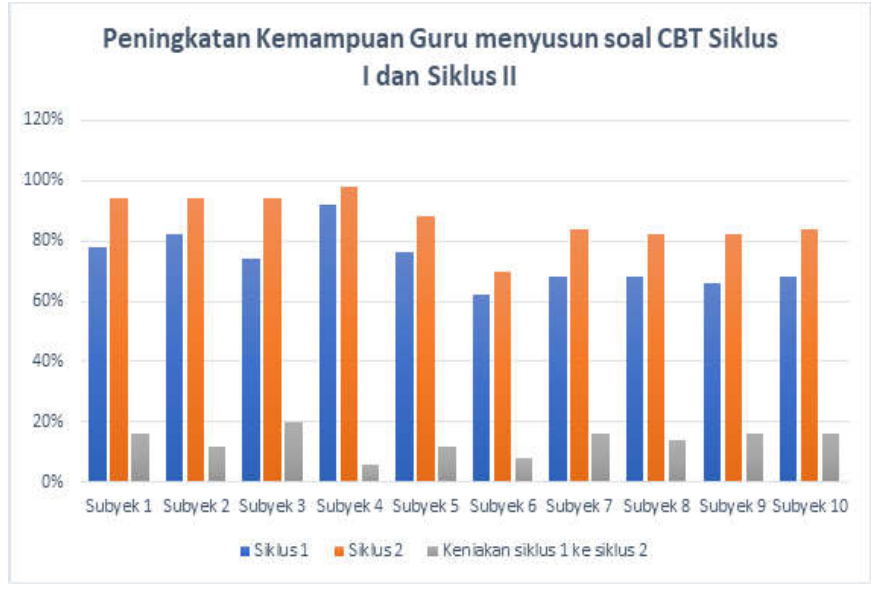

Gambar 3: Kemampuan Guru menyusun soal CBT Siklus I dan Siklus II

Bentuk aktifitas guru dalam peningkatan kemampuan guru dalam Menyusun soal CBT terdiri dari: 1) Membuat soal CBT (Pembuatan soal di Ms. Word, Input soal Ms. Word ke Ms. Excel, Pembuatan 
File Pendukung (Audio, Video, \& Gambar); 2) Mengolah Data (Membuat daftar kelas, Membuat daftar mata pelajaran, Membuat daftar siswa dan Menginput soal ke aplikasi; 3) Mengaktifkam soal, (Mengaktifkan mapel yang akan diujikan Aktifasi jadwal Ujian); 4) Mengaktifkan examp. Hsil aktifitas tersubut dapat di lihat seperti pada Gambar 4.

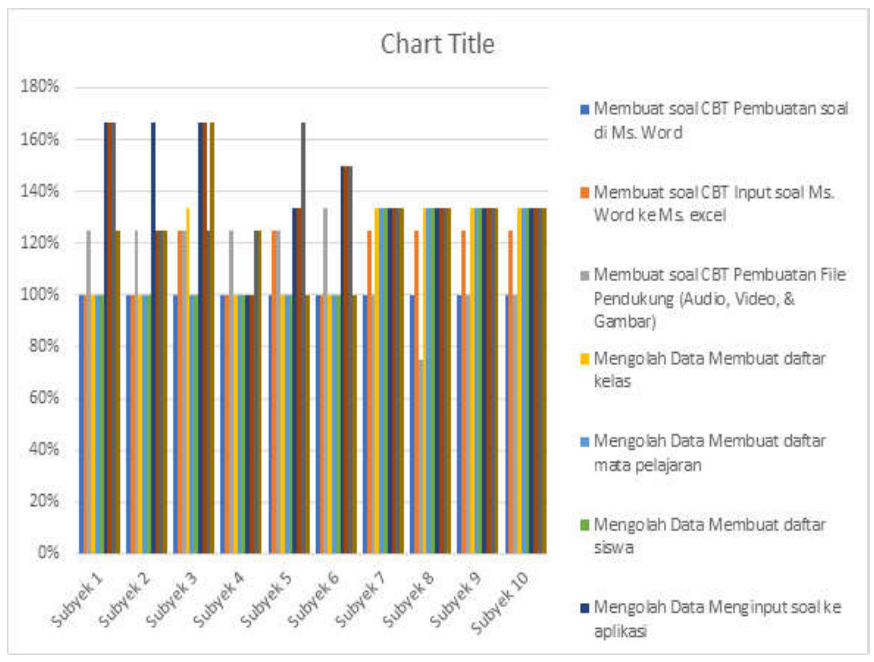

Gambar 4: Aktivitas Guru menyusun soal CBT

Secara umum, temuan penelitian mengungkapkan bahwa telah terjadi peningkatan kemampuan seluruh guru dalam menyusun soal soal CBT seperti terlihat pada tabel di atas, ada 1 guru yang belum berhasil menyelesaikan penyusunan soal CBT dengan baik seperti yang ditargetkan. Temuan penelitian ini serupa dengan penelitian (Murniati 2016) menemukan bahwa hasil belajar kearsipan siswa meningkat ketika menggunakan instrumen CBT. Sehingga disimpulkan instrumen evaluasi pembelajaran kearsipan CBT lebih efektif dibandingkan tanpa menggunakan instrumen evaluasi pembelajaran CBT. Namun demikian penelitian penelitian tersebut hampir belum ada yang menggunakan IHT sebagai alternatif pelatihan untuk meningkatkan kemampuan guru menyusun soal CBT, oleh karena itu penelitian menganggap bahwa pelatihan melalui IHT dapat meningkatkan kemampuan guru dalam menyusun soal CBT.

In-house training dilaksanakan secara internal oleh kelompok kerja guru sekolah atau tempat lain yang ditetapkan untuk tempat penyelenggaraan pelatihan, dilakukan berdasar pada pemikiran bahwa sebagian peningkatan kompetensi dan karier guru tidak harus dilakukan secara eksternal, tetapi dapat juga dilakukan secara internal oleh guru sebagai trainer yang sudah memiliki kompetensi yang belum dimiliki oleh guru lain. Ketentuan untuk peserta dalam in house training minimal sejumlah 4 orang dan maksimal 15 orang.

In house training merupakan pelatihan dengan berbagai tujuan atau kebutuhan tertentu sebuah perusahaan. Beberapa tujuan dari kegiatan In-House Training diantaranya: (1) Meningkatkan kualitas Sumber Daya Manusia (SDM) perusahaan terkait. Kegiatan ini untuk mendukung target organisasi dalam mencapai sasaran yang telah ditetapkan oleh perusahaan, sesuai visi dan misi organisasi; (2) Menciptakan interaksi antara peserta. Sebuah perusahaan/ organsisasi, atau instansi yang memiliki banyak cabang di berbagai daerah kemungkinan memiliki cara kerja, pengalaman kerja dan pengalaman hidup dan memiliki kualitas yang berbeda pula. In House_Training memungkinkan peserta dapat bertukar informasi sehingga lebih efektif untuk menciptakan standarisasi kinerja, sehingga semua cabang bisa berkembang secara merata dengan kualitas terstandar; (3) Mempererat rasa kekeluargaan dan kebersamaan antara karyawan dalam satu komunitas besar sehingga dapat sharing secara bersahabat dan lebih kompak. Perusahaan dapat diuntungkan dengan adanya kegiatan ini; (4) Motivasi dan budaya belajar yang berkesinambungan dapat meningkat dengan mengeksplorasi permasalahan-permasalahan yang dihadapi di lapangan yang berkaitan dengan peningkatan efektifitas kerja, sehingga dapat mencari solusi kemungkinan terbaik secara bersama-sama. Masih banyak lagi tujuan dan manfaat in house training yang biasanya diharapkan oleh para penyelenggara (Indomitra 2012) 


\section{SIMPULAN DAN SARAN}

Hasil penelitian mengungkapkan bahwa prosentasi kemampuan guru menyusun soal CBT meningkat dari $60 \%$ pada siklus I menjadi $87 \%$ pada siklus II. Kemampuan menyusun CBT meliputi perancangan soal, pembuatan file pendukung, dan pengaktifan soal di komputer. Selain itu aktivitas guru di dalam IHT meningikat dari $73 \%$ pada siklus I menjadi $87 \%$ pada sikulus II. Simpulan penelitian ini adalah kemampuan menyusun soal CBT dan aktivitas guru dapat ditingkatkan melalui In house training

Sebagai bagian akhir dari penulisan ini, penulis memberikan saran bahwa guru yang belum menguasai kemampuan dalam penyusunan soal CBT hendaknya selalu diberikan pembinaan keterampilan komputer, dengan cara pendampingan dan diberi tambahan waktu untuk menyelesaikan penyusunan kelengkapan mengajar. Dan bagi guru yang telah berhasil dalam penyusunan soal CBT harus selalu dipantau dan dibina agar lebih meningkat ketrampilannya dan dapat mengembangkannya lebih luas lagi.

\section{PUSTAKA ACUAN}

Arsyad, Azhar. 2014. Media Pembelajaran. Jakarta: Raja Grafindo Persada.

Indomitra, Pranta. 2012. "Meningkatkan Kualitas SDM Dengan In House Training." 2012. https://pratamaindomitra.co.id/in-housetraining-meningkatkan-kualitas-sdm-dengan-in-house-training.html?v=b718adec73e0.

Kemdiknas. 2010. Penelitian Tindakan Sekolah. Jakarta: Kemdiknas.

Murniati, Evi. 2016. Computer Based Test (CBT) Sebagai Alternatif Instrumen Evaluasi Pembelajaran. Surakarta: PPs UNS Surakarta. Saad, Al-Amri. 2007. "Computer-Based vs. Paper-Based Testing: Does the Test Administration Mode Matter." In . 